\title{
Identification of viridans streptococci on the Minitek Miniaturised Differentiation System
}

\author{
YVETTE HOLLOWAY, MARIJKE SCHAAREMAN, AND J. DANKERT \\ From the Laboratory for Medical Microbiology, Department of Hospital Epidemiology, University \\ Hospital of Groningen, The Netherlands
}

SUMMARY A total of 227 strains of viridans streptococci were simultaneously identified on the Minitek Miniaturised System (BBL) and by a conventional method according to Colman and Williams. The Minitek discs were each overlaid with a drop of sterile liquid paraffin, and the trays were incubated in GasPak jars (BBL) with $\mathrm{CO}_{2}$ generator envelopes. Identification was possible three to four days earlier than with the conventional method. The results were found to be in agreement with the conventional method. Compared to the identification schemes of Cowan and Steel and of Facklam, the results were also in good agreement. Minor differences were found in the number of positive and negative results in those reactions that are variable in all three schemes.

Identification of the different species within the socalled viridans streptococci group has become more important in the last decade. Streptococcus mutans, one of the members of the viridans streptococci group, has attracted interest for its possible causative relationship to dental caries (Gibbons and Fitzgerald, 1969). Infective endocarditis due to the viridans group is well recorded (Johnson et al., 1975), and it has been shown that especially Strep. mutans, Strep. sanguis, and Strep. mitior have been involved (Parker and Ball, 1976). It is therefore important to be able to subdivide the viridans group into species.

The conventional methods for the identification of this group are time-consuming. An average of three to five days elapses before carbohydrate reactions can be read with certainty.

The use of the Minitek Miniaturised Differentiation System for the identification of the Enterobacteriaceae is well recorded (Hansen et al., 1974; Kiehn et al., 1974; Finklea et al., 1976). The system has also been sucessfully employed for the identification of anaerobic bacteria (Hansen and Stewart, 1976; Stargel et al., 1976). We therefore decided to run a short trial on the identification of viridans streptococci on this system.

\section{Material and methods}

STREPTOCOCCI TESTED

Two hundred and twenty-seven strains of viridans

Received for publication 24 April 1979 streptococci were identified simultaneously on the Minitek Differentiation System and by a conventional method (Colman and Williams, 1972) using Hiss-serum broth with Andrade's indicator. One strain of each of the five species of the strepto-? cocci was obtained from Dr J. H. J. Huis in 't Veld, Department of Preventive Dentistry, State University, Utrecht. The other 222 streptococci were clinical isolates. Haemolysis was determined on sheep blood agar $(5 \% \mathrm{v} / \mathrm{v})$ and 'greening' demonstrated on chocolate agar, incubated with and without $\mathrm{CO}_{2}$. All streptococci were tested for sensitivity to bacitracin and optochin by the disc method (Oxoid, Ltd). Strep. faecalis and Strep. pneumoniae were excluded by conventional methods. Beta-haemolytic streptococci were not included in the trial.

MINITEK DIFFERENTIATION SYSTEM

The Minitek System offers a choice of paper discs impregnated with substrate. We used the following discs: trehalose, raffinose, arabinose, mannitol, glycerol, lactose, maltose, sorbitol, salicin, sucrose, and aesculin. This choice was determined by the discs already available in this laboratory for identification of anaerobes, and we do not claim it to be ideal. We would have liked to include melibiose and inulin.

The discs are dispensed into the wells of a plastic Minitek tray using a dispenser which delivers 10 discs in one movement. Besides the substrate, the discs contain phenol red indicator, which turns 1168 
yellow on production of acid. The aesculin disc becomes black when aesculin is hydrolysed.

A suspension of each streptococcus to be tested was made in the inoculum broth (Lombard and Dowell broth) supplied by the manufacturer for anaerobic organisms. The inoculum was made to the same density as a McFarland No. 5 standard. Each disc was inoculated with approximately $0.05 \mathrm{ml}$ of the suspension, using the automatic pipette supplied with the system. Each well was then covered with 1 drop of sterile liquid paraffin, and the plastic tray was incubated at $37^{\circ} \mathrm{C}$ in GasPak jars containing $\mathrm{CO}_{2}$ generator envelopes for 18 hours.

After incubation the trays were removed from the jars, and the results were recorded. Then 1 to 2 drops of $0.025 \%(\mathrm{v} / \mathrm{v})$ phenol red was added to each well, and the results were compared. Despite the paraffin overlay, the phenol red reaches the discs. Only a clearly yellow colour was taken to be positive; any shade of orange or red was considered to be negative.

The aesculin disc was always clearly black when positive and colourless when negative. One drop of ferric ammonium citrate $(1 \%)$ was always added for confirmation.

\section{CONVENTIONAL TESTS AND ADDITIONAL}

\section{MEDIA USED}

Streptococci were identified according to Colman and Williams (1972) using Hiss-serum broth with Andrade's indicator for acid production. The following tests were omitted, some because they were not available and others because they are beyond our scope: sensitivity to nitrofurazone, growth on bile agar and in $\mathrm{NaCl}$ broth, acid production from inulin, hydrolysis of starch, hyaluronidase production, acetylmethylcarbinol production from glucose, and cell wall carbohydrates were not analysed. In addition, we tested production of acid from arabinose and maltose, production of dextran or laevan on sucrose agar (de Stoppelaar, 1971), MSFA agar (Linke, 1977), and Mitis-Salvarius agar, and production of $\mathrm{H}_{2} \mathrm{O}_{2}$ on benzidine agar (Kraus et al., 1957). Haemolysis or absence thereof was always determined on both blood and chocolate agar medium, where 'greening' of chocolate agar was taken to denote alphahaemolysis.

Arginine hydrolysis was performed according to Cowan (1975), adding Nessler's reagent after 18 hours' incubation at $37^{\circ} \mathrm{C}$.

Sucrose agar $(5 \% \mathrm{w} / \mathrm{v})$ was prepared according to de Stoppelaar (1971). The composition of this medium is Bacto-Casitone (Difco) $15 \mathrm{~g}$, yeast extract (Difco) $5 \mathrm{~g}$, L-cysteine $0 \cdot 2 \mathrm{~g}, \mathrm{Na}_{2} \mathrm{SO}_{3} \mathrm{O} \cdot 1 \mathrm{~g}$, $\mathrm{NaCl} 1$ g, $\mathrm{Na}_{2} \mathrm{HPO}_{4} \cdot 12$ aq. 2 g, $\mathrm{NaHCO}_{3} 2 \mathrm{~g}$, sodium acetate 3 aq. $20 \mathrm{~g}$, sucrose $50 \mathrm{~g}$, and Bacto agar (Difco) $15 \mathrm{~g}$ per litre, $\mathrm{pH} \mathrm{7 \cdot 3}$. The plates were incubated under $\mathrm{CO}_{2}$, and the production of dextran or laevan could always be clearly seen after 18 hours.

MSFA agar was prepared according to Linke (1977) and incubated under $\mathrm{CO}_{2}$. We found that these plates needed to be incubated for $\mathbf{4 8}$ hours and sometimes longer.

The Mitis-Salivarius agar used (Oxoid, Ltd) was prepared as directed. The plates were incubated under $\mathrm{CO}_{2}$ and could always be read after 18 hours' incubation. Formation of dextran or laevan could also be seen on these plates.

Benzidine agar was prepared according to Kraus et al. (1957) and also incubated under $\mathrm{CO}_{2}$. Formation of $\mathrm{H}_{2} \mathrm{O}_{2}$, characterised by blackening of the media around the colonies, was mostly clear after 18 hours' incubation. It is noted that benzidine is carcinogenic, and special precautions need to be taken when the medium is prepared. A theatre mask should be worn at all times while benzidine is being handled for preparation of the media, and the powder should be weighed in an enclosed balance to avoid dispersal. Preferably, the powder should be weighed in a ventilation cupboard with negative pressure, working with gloves.

\section{Results}

Two hundred and twenty-seven strains of viridans streptococci were identified using the Minitek Differentiation System and a conventional method according to Colman and Williams (1972). The results are listed in Table 1 . No discrepancies or false results were found. Minor differences were found in the number of positive and negative results in those reactions which are variable. Variability was found in both identification systems, depending on the species tested. In the Minitek System the salicin disc was found to give variable results for all strains tested.

The suspension broth used for the viridans streptococci was the anaerobic inoculum broth supplied by BBL for anaerobic microorganisms. This was found to give more reliable results than Todd-Hewitt broth, glucose broth, serum broth, or chopped meat glucose, all of which we also tested.

Incubation was in a $\mathrm{CO}_{2}$ atmosphere in GasPak jars. Incubation in candle jars was also tried and did not affect the results, but GasPak jars speeded up the reaction. Incubation in an ordinary incubator, with or without a paraffin overlay, or incubation in $\mathrm{CO}_{2}$ without paraffin gave false results. We have no explanation for the success of the liquid paraffin overlay, except that possibly it prevents the discs from drying out and it supplies anaerobic conditions. 
Table 1 Results of 227 strains of viridans streptococci obtained with 11 tests comparing the Minitek System $(A)$ and the method of Colman and Williams $(B)$

\begin{tabular}{|c|c|c|c|c|c|c|}
\hline \multirow[t]{2}{*}{ Substrate } & & \multicolumn{5}{|c|}{ Viridans streptococci tested } \\
\hline & & $\begin{array}{l}\text { Strep. mutans } \\
\text { (29 strains) }\end{array}$ & $\begin{array}{l}\text { Strep. sanguis } \\
(30 \text { strains })\end{array}$ & $\begin{array}{l}\text { Strep. salivarius } \\
\text { (24 strains) }\end{array}$ & $\begin{array}{l}\text { Strep. milleri } \\
\text { (27 strains) }\end{array}$ & $\begin{array}{l}\text { Strep. mitior } \\
\text { (117 strains) }\end{array}$ \\
\hline Trehalose & $\begin{array}{l}\mathbf{A} \\
\mathbf{B}\end{array}$ & $\stackrel{+}{+}$ & $+^{+}$ & $\begin{array}{l}+ \\
+\end{array}$ & $\begin{array}{l}+- \\
+-\end{array}$ & $\begin{array}{l}i^{+} \\
+\end{array}$ \\
\hline Raffinose & A & $\begin{array}{l}-^{+} \\
+\end{array}$ & $\begin{array}{l}-^{+} \\
-^{+}\end{array}$ & + & $\begin{array}{l}-^{+} \\
-^{+}\end{array}$ & $\begin{array}{l}-+ \\
-^{+}\end{array}$ \\
\hline Arabinose & $\begin{array}{l}\mathbf{A} \\
\mathbf{B}\end{array}$ & $\overline{\mathrm{ND}}$ & $\overline{N D}$ & $\overline{\mathrm{ND}}$ & $\overline{N D}$ & $\overline{N D}$ \\
\hline Mannitol & $\begin{array}{l}\mathbf{A} \\
\mathbf{B}\end{array}$ & $\stackrel{+}{+}$ & $\overline{-}$ & $\overline{-}$ & $\overline{-}^{+}$ & - \\
\hline Glycerol & $\begin{array}{l}\mathbf{A} \\
\mathbf{B}\end{array}$ & $\overline{-}_{+}$ & - & $\overline{-}$ & $\overline{-}$ & $\overline{-}$ \\
\hline Lactose & $\begin{array}{l}\mathbf{A} \\
\mathbf{B}\end{array}$ & $\begin{array}{l}+- \\
+\end{array}$ & $\begin{array}{l}-^{+} \\
+^{-}\end{array}$ & $\begin{array}{l}+- \\
+^{-}\end{array}$ & $\begin{array}{l}+- \\
+-\end{array}$ & $\begin{array}{l}+^{-} \\
+^{-}\end{array}$ \\
\hline Maltose & $\begin{array}{l}\mathbf{A} \\
\mathbf{B}\end{array}$ & $\stackrel{+}{\text { ND }}$ & $\stackrel{+}{\text { ND }}$ & $\stackrel{+}{\text { ND }}$ & $\stackrel{+}{\text { ND }}$ & $\stackrel{+}{\text { ND }}$ \\
\hline Sorbitol & $\begin{array}{l}\mathbf{A} \\
\mathbf{B}\end{array}$ & $\begin{array}{l}+- \\
+-\end{array}$ & $\overline{-}$ & $\overline{-}$ & $\overline{-}^{+}$ & $\overline{-}$ \\
\hline Salicin & $\begin{array}{l}\mathbf{A} \\
\mathbf{B}\end{array}$ & $\begin{array}{l}+- \\
+\end{array}$ & $\begin{array}{l}+- \\
+-\end{array}$ & $\stackrel{+-}{+}$ & $\begin{array}{l}+- \\
+\end{array}$ & $\begin{array}{l}-^{+} \\
-^{+}\end{array}$ \\
\hline Sucrose & $\begin{array}{l}\mathbf{A} \\
\mathbf{B}\end{array}$ & + & + & $\stackrel{+}{+}$ & $\begin{array}{l}+- \\
+^{-}\end{array}$ & $\begin{array}{l}+- \\
+-\end{array}$ \\
\hline Aesculin & $\begin{array}{l}\mathbf{A} \\
\mathbf{B}\end{array}$ & + & $\begin{array}{l}+^{-} \\
+^{-}\end{array}$ & $\begin{array}{l}+ \\
+\end{array}$ & $\begin{array}{l}+- \\
+^{-}\end{array}$ & $\begin{array}{l}-^{+} \\
-+\end{array}$ \\
\hline
\end{tabular}

+ positive in all strains tested

- +positive in $25 \%$ or less of strains tested

+ -positive in up to $75 \%$ of strains tested

- negative in all strains

ND not determined

In this case it is possible that a $\mathrm{H}_{2}+\mathrm{CO}_{2}$ generator envelope would serve as well, together with a catalyst, as this would provide moisture and the same anaerobic conditions. To test this hypothesis, a short trial was done on 20 viridans streptococci using GasPak envelopes generating $\mathrm{H}_{2}+\mathrm{CO}_{2}$ and incubating without paraffin overlay. The same 20 streptococci were simultaneously incubated with $\mathrm{CO}_{2}$ generator envelopes, as described. The two sets of results were found to be identical after 24 hours' incubation at $37^{\circ} \mathrm{C}$.

The Minitek trays could always be read after 18 hours' incubation, and results were always clear, even before addition of phenol red. It was always possible to give an identification within 24 hours, while with the conventional system this was often delayed for up to five days.

In Table 2 we have listed the results obtained with these 227 strains of viridans streptococci with the Minitek System and compared these results with the identification schemes given by Cowan (1975) and Facklam (1977). The results are in good agreement. Small variations were found in all three systems. Whereas, compared to the scheme of Colman and Williams (1972), salicin gave a more variable result (Table 1), the Minitek System compares well with the identification scheme of Facklam (1977), who also found variable results with salicin.

Additional tests were necessary, as it is of course not possible to identify streptococci on carbohydrate fermentation and aesculin hydrolysis alone. The tests and media used are haemolysis, arginine hydrolysis, sucrose agar, Mitis-salivarius agar, MSFA agar, and benzidine agar (Table 3). Except for the MSFA agar and, on rare occasions the benzidine agar, these could all be read after 18 hours' incubation.

The hydrogen peroxide production of Strep. 
Table 2 Results of 227 strains of viridans streptococci obtained with 11 tests using the Minitek System $(A)$, in comparison with the identification schemes given by Cowan and Steel $(C)$ and Facklam $(D)$

\begin{tabular}{|c|c|c|c|c|c|c|}
\hline \multirow[t]{2}{*}{ Substrate } & & \multicolumn{5}{|c|}{ Viridans streptococci tested } \\
\hline & & $\begin{array}{l}\text { Strep. mutans } \\
\text { (29 strains) }\end{array}$ & $\begin{array}{l}\text { Strep. sanguis } \\
\text { ( } 30 \text { strains) }\end{array}$ & $\begin{array}{l}\text { Strep. salivarius } \\
\text { (24 strains) }\end{array}$ & $\begin{array}{l}\text { Strep. milleri* } \\
\text { (27 strains) }\end{array}$ & $\begin{array}{l}\text { Strep. mitior } \\
\text { (117 strains) }\end{array}$ \\
\hline & $\mathbf{A}$ & + & -+ & + & $+^{-}$ & -+ \\
\hline \multirow[t]{3}{*}{ Trehalose } & C & + & $t^{-}$ & + & + & $+^{-}$ \\
\hline & D & + & $+^{-}$ & $t^{-}$ & $+^{-}$ & -+ \\
\hline & $\mathbf{A}$ & -+ & -+ & + & -+ & -+ \\
\hline \multirow[t]{3}{*}{ Raffinose } & C & $+^{-}$ & $+^{-}$ & $+^{-}$ & $+^{-}$ & $t^{-}$ \\
\hline & D & $t^{-}$ & $t^{-}$ & $i^{-}$ & -+ & - \\
\hline & $\mathbf{A}$ & - & - & - & - & - \\
\hline \multirow[t]{3}{*}{ Arabinose } & C & ND & ND & ND & ND & ND \\
\hline & D & - & - & - & - & - \\
\hline & $\mathbf{A}$ & + & - & - & - & - \\
\hline \multirow[t]{3}{*}{ Mannitol } & C & + & - & - & - & - \\
\hline & D & + & - & - & - & - \\
\hline & $\mathbf{A}$ & - & - & - & - & - \\
\hline \multirow[t]{3}{*}{ Glycerol } & C & - & - & - & - & - \\
\hline & D & - & - & - & - & - \\
\hline & $\mathbf{A}$ & $+^{-}$ & $-^{+}$ & $t^{-}$ & +- & $+^{-}$ \\
\hline \multirow[t]{3}{*}{ Lactose } & C & + & + & + & + & $i^{-}$ \\
\hline & $\mathbf{D}$ & +- & +- & +- & + & + \\
\hline & $\overrightarrow{\mathbf{A}}$ & + & + & + & + & + \\
\hline \multirow[t]{3}{*}{ Maltose } & C & + & + & + & + & + \\
\hline & $\mathbf{D}$ & ND & ND & ND & ND & ND \\
\hline & $\mathbf{A}$ & $+^{-}$ & - & - & - & - \\
\hline \multirow[t]{3}{*}{ Sorbitol } & $\mathbf{C}$ & + & - & - & - & - \\
\hline & D & +- & $-^{+}$ & - & - & - \\
\hline & $\overline{\mathbf{A}}$ & +- & +- & $t^{-}$ & $t^{-}$ & $-^{+}$ \\
\hline \multirow[t]{3}{*}{ Salicin } & $\mathbf{C}$ & + & + & + & + & - \\
\hline & D & $+^{-}$ & $+^{-}$ & +- & +- & -+ \\
\hline & $\mathbf{A}$ & + & + & + & +- & +- \\
\hline \multirow[t]{3}{*}{ Sucrose } & C & + & + & + & + & + \\
\hline & D & + & $+^{-}$ & + & + & + \\
\hline & $\mathbf{A}$ & + & $+^{-}$ & + & $t^{-}$ & -+ \\
\hline \multirow[t]{2}{*}{ Aesculin } & C & $t^{-}$ & +- & + & +- & - \\
\hline & $\mathbf{D}$ & $+^{-}$ & +- & +- & + & - \\
\hline
\end{tabular}

+ positive in all strains tested

- ${ }^{+}$positive in $25 \%$ or less of strains tested

+ -positive in up to $75 \%$ of strains tested

- negative in all strains

ND not determined

*In Facklam's nomenclature this is Streptococcus MG intermedius.

mitior on benzidine agar was sometimes weak after 18 hours, although it could be recognised MSFA agar was used more for confirmation than for identification.

\section{Discussion}

The viridans streptococci are a group whose characteristics include a 'formidable list of exceptions' (Cowan 1975). A great deal of work has been done by Colman and Williams (1972), Cowan (1975), and Facklam (1977) to provide a viable classification system for these microorganisms.

In view of the difficulties encountered, it is not possible to agree with O'Keefe and Gorbach (1978), who state that 'the correct identification of streptococci can be accomplished with a small number of simple laboratory tests'. The number of such tests required is not small, nor has it ever been simple. The list advocated by Cowan (1975) contains 25 tests; that of Facklam (1977) contains 30 tests; and Colman and Williams (1972) used 24 tests for their classification scheme.

Viridans streptococci are found in $54 \%$ of cases of streptococcal bacteraemia, which constitutes $19 \%$ of all bacteraemia (Horstmeier and Washington, 1973). These organisms are found in $30 \%$ to $45 \%$ of cases of infective endocarditis (Finland and Barnes, 1970; Schnurr et al., 1977).

It is especially important to be able to differentiate Strep. mutans from the other viridans streptococci because of its abundant production of dextran, a virulence factor which might be implicated in both infective endocarditis (Pelletier et al., 1978) and 
Table 3 Six additional tests used for the identification of viridans streptococci

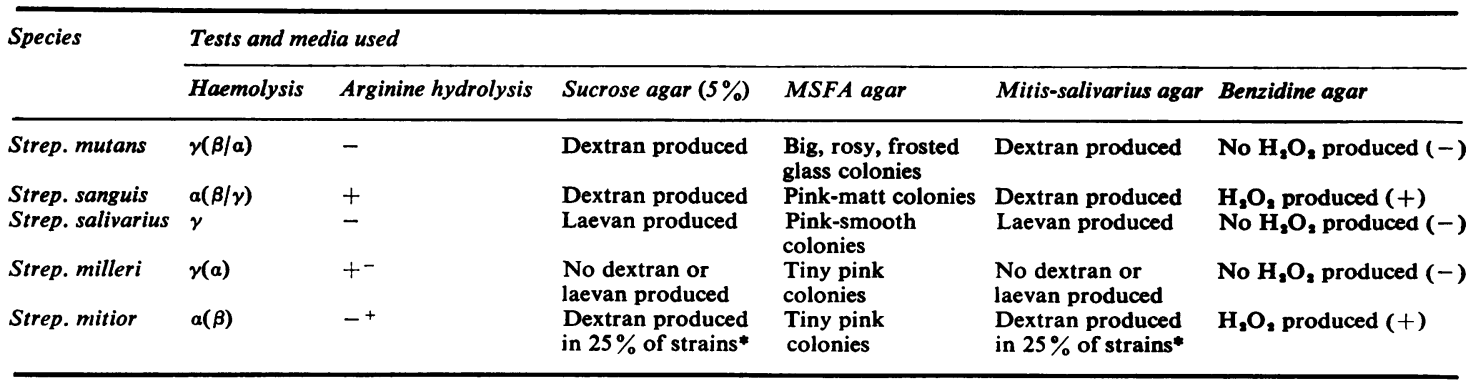

*according to Facklam (1977)

caries (Gibbons, 1972). Strep. sanguis and Strep. mitior are also known to produce dextran (Facklam, 1977).

In a running project on streptococci found in subacute bacterial endocarditis, we need to identify a large number of viridans streptococci isolated from teeth and gingival swabs. This is time-consuming work, and, in view of the success experienced in the identification of anaerobes on the Minitek System (Hansen and Stewart, 1976; Stargel et al., 1976), we decided to attempt the identification of viridans streptococci by this means. Using the Minitek System, and applying a liquid paraffin overlay and incubation in an atmosphere of $\mathrm{CO}_{2}$, we have found it possible to identify viridans streptococci some days earlier than was previously possible with the conventional system used, where the production of acid sometimes took five days to become visible.

Although Minitek gives faster results of carbohydrate fermentation, the use of additional tests is still necessary for a complete identification of viridans streptococci. In combination with the 11 substrate discs used, we found the use of, especially, sucrose agar, benzidine agar, and arginine hydrolysis to be essential.

Selective media (MSFA agar and Mitis-salivarius agar) were necessary not only for primary isolation from mixed cultures but also for confirmation of identification. We agree with Loesche and Syed (1973) that selective media are used 'at a price', and for this reason we always use plain blood agar and chocolate agar as well for the initial isolation of the viridans streptococci.

The Minitek trays are small and can be conveniently stacked in GasPak jars with no spillage. A great deal of time is saved, and we have calculated that the cost is no greater than that of preparing the conventional media, especially since we started making our own inoculum broth according to the instructions provided by the manufacturer.
We thank Mr J. Staal for preparation of the media required.

\section{References}

Colman, G., and Williams, R. E. O. (1972). Taxonomy of some human viridans streptococci. In Streptococci and Streptococcal Diseases, edited by L. W. Wannamaker and J. M. Matsen, pp. 281-299. Academic Press, New York and London.

Cowan, S. T. (1975). Cowan and Steel's Manual for the Identification of Medical Bacteria. 2nd edition. Cambridge University Press, London and Cambridge.

de Stoppelaar, J. D. (1971). Streptococcus mutans, Streptococcus sanguis and dental caries. Thesis, Rijksuniversiteit Utrecht.

Facklam, R. R. (1977). Physiological differentiation of viridans streptococci. Journal of Clinical Microbiology, 5, 184-201.

Finklea, P. J., Cole, M. S., and Sodeman, T. M. (1976). Clinical evaluation of the Minitek Differential System for identification of Enterobacteriaceae. Journal of Clinical Microbiology, 4, 400-404.

Finland, M., and Barnes, M. W. (1970). Changing etiology of bacterial endocarditis in the antibacterial era. Annals of Internal Medicine, 72, 341-348.

Gibbons, R. J. (1972). Ecology and cariogenic potential of oral streptococci. In Streptococci and Streptococcal Diseases, edited by L. W. Wannamaker and J. M. Matsen, pp. 371-385. Academic Press, New York and London.

Gibbons, R. J., and Fitzgerald, R. J. (1969). Dextraninduced agglutination of Streptococcus mutans, and its potential role in the formation of microbial dental plaques. Journal of Bacteriology, 98, 341-346.

Hansen, S. L., Hardesty, D. R., and Myers, B. M. (1974). Evaluation of the BBL Minitek System for the identification of Enterobacteriaceae. Applied Microbiology, 28, 798-801.

Hansen, S. L., and Stewart, B. J. (1976). Comparison of API and Minitek to Center for Disease Control methods for the biochemical characterization of anaerobes. Journal of Clinical Microbiology, 4, 227-231. Horstmeier, C., and Washington, J. A. (1973). Micro- 
biological study of streptococcal bacteremia. Applied Microbiology, 26, 589-591.

Johnson, D. H., Rosenthal, A., and Nadas, A. S. (1975). A forty-year review of bacterial endocarditis in infancy and childhood. Circulation, 51, 581-588.

Kiehn, T. E., Brennan, K., and Ellner, P. D. (1974). Evaluation of the Minitek System for identification of Enterobacteriaceae. Applied Microbiology, 28, 668-671.

Kraus, F. W., Nickerson, J. F., Perry, W. I., and Walker, A. P. (1957). Peroxide and peroxidogenic bacteria in human saliva. Journal of Bacteriology, 73, 727-735.

Linke, H. A. B. (1977). New medium for the isolation of Streptococcus mutans and its differentiation from other oral streptococci. Journal of Clinical Microbiology, 5, 604-609.

Loesche, W. J., and Syed, S. A. (1973). The predominant cultivable flora of carious plaque and carious dentine. Caries Research, 7, 201-216.

O'Keefe, J. P., and Gorbach, S. L. (1978). Laboratory diagnosis of infective endocarditis. In Infective Endocarditis, edited by S. H. Rahimtoola, pp. 307-325. Grune and Stratton, New York.
Parker, M. T., and Ball, L. C. (1976). Streptococci and aerococci associated with systemic infection in man. Journal of Medical Microbiology, 9, 275-302.

Pelletier, L. L., Jr., Coyle, M., and Petersdorf, R. (1978). Dextran production as a possible virulence factor in streptococcal endocarditis. Proceedings of the Society for Experimental Biology and Medicine, 158, 415-420.

Schnurr, L. P., Ball, A. P., Geddes, A. M., Gray, J., and McGhie, D. (1977). Bacterial endocarditis in England in the 1970's: A review of 70 patients. Quarterly Journal of Medicine, 46, 499-512.

Stargel, M. D., Thompson, F. S., Philips, S. E., Lombard, G. L., and Dowell, V. R., Jr. (1976). Modification of the Minitek Miniaturized Differentiation System for characterization of anaerobic bacteria. Journal of Clinical Microbiology, 3, 291-301.

Requests for reprints to: J. Dankert, Laboratory for Medical Microbiology, University Hospital of Groningen, Oostersingel 59, Groningen, The Netherlands. 